\title{
A banalidade do mal psicofarmacológico em tempos de performance
}

\author{
Maicon Cunha* (1) \\ Universidade Estácio de Sá, Círculo Psicanalítico do Rio de Janeiro**, Rio de Janeiro, RJ, Brasil
}

Resumo: Este artigo tem por objetivo percorrer um caminho que parte da identificação do fenômeno da medicalização da vida. $O$ estudo será organizado dentro de uma perspectiva genealógica, na medida em que é importante localizar que este objeto de estudo não se restringe apenas a uma questão médica, mas exige um esforço de articulação com outras áreas do saber. Assim, esta genealogia articula questões médicas com a crítica social acerca desse fenômeno, aliando medicina, sociologia, psicologia, economia e teoria política. $O$ desenvolvimento será organizado tendo como pano de fundo as exigências de autonomia e performance na atualidade, no contexto do aumento da demanda psicofarmacológica. Se os benefícios da administração medicamentosa podem propiciar bem-estar subjetivo, por outro lado, os excessos ou a banalidade do mal psicofarmacológico tornam opacas as fronteiras entre o normal e o patológico.

Palavras-chave: psicofarmacologização, performance, neoliberalismo, indústria farmacêutica.

\section{Introdução: uma visão acerca do campo das drogas na atualidade}

Presencia-se na atualidade um aumento vertiginoso da demanda por psicofármacos em vários níveis e instâncias da sociedade (Conrad, 2007). A indústria farmacêutica vende a imagem de seus produtos como a possibilidade de alcançar uma desejada quietude, que se revelaria no aplacamento de conflitos e tensões; haveria, assim, a possibilidade de obter certa felicidade em pílulas. Era exatamente essa promessa que estava na base do marketing do Prozac, que começou a ser difundido no final da década de 1980 . Um verdadeiro boom no consumo de psicofármacos se nota no nosso cotidiano e em um ritmo cada vez maior.

Borch-Jacobsen (2013) afirma que se intensificou a industrialização da farmácia nos anos 1930 e 1940 com a introdução generalizada dos antibióticos, que foram os primeiros medicamentos de massa. Segundo o autor, até 1930 havia apenas medicamentos eficazes para um grupo de sete doenças. A expansão dessa indústria se adensou depois da Segunda Guerra Mundial, estimulada por uma série de descobertas científicas sobre as substâncias químicas. No entanto, nos anos 1980 e 1990, houve aumento da produção sob a égide de algumas grandes companhias, graças a fusões entre elas.

No amplo estudo de Borch-Jacobsen (2013) há dados da IMS Health de que o volume de negócios da indústria farmacêutica era, a nível mundial, de 400 bilhões de dólares em 2002. Em 2008, esse número passou para 775 bilhões e, em 2011, já ultrapassava 956 bilhões de dólares 1 .

Esses números colocam a indústria farmacêutica como um dos negócios mais lucrativos do mundo. A classe dos medicamentos com maior volume de negócios mundial em 2008 era a dos psicofármacos, seguida de estatinas para o controle do colesterol, tratamento para a asma, os antidiabéticos e os antiulcerosos para refluxo gástrico, sendo que os psicofármacos avolumavam 60 bilhões de dólares, enquanto o segundo maior volume, as estatinas, movimentava um negócio em torno de 33 milhões de dólares.

Certamente, esse é um debate que segue um ritmo que aumenta intensamente também em relação ao interesse acadêmico. Em uma rápida pesquisa na base de dados da Coordenação de Aperfeiçoamento de Pessoal de Nível Superior (Capes) ${ }^{2}$, em agosto de 2014, a busca pelo termo "medicalização" mostrou 361 resultados de artigos, dispostos cronologicamente da seguinte forma: antes de 1998 (cinco artigos), 1998-2001 (dez artigos), 2002-2005 (22 artigos), 2006-2009 (157 artigos), 2010-2014 (168 artigos). Em outra pesquisa com o mesmo termo em agosto de 2019, na mesma base de dados, revelou que o número de artigos saltava para 1.037, aumento de mais de $100 \%$ em cinco anos. Tais dados refletem que há no cenário atual um interesse crescente pela problemática referida aos psicofármacos.

Não é uma novidade que muito já se discutiu sobre as drogas ilícitas no campo das toxicomanias. No entanto estamos diante de um quadro que organiza as coordenadas

\footnotetext{
* Endereço para correspondência: mpcrj1@gmail.com

** Membro associado em formação.
}

1 Em janeiro de 2012, o valor de mercado global da indústria farmacêutica se situava a 1.600 bilhão de dólares, na terceira posição, atrás somente do setor de seguro bancário (4 mil bilhões de dólares) e das companhias petrolíferas (3.400 bilhões de dólares)

2 Recuperado de https://bit.ly/3xjfFye 
de um processo de intensa psicofarmacologização ${ }^{3}$ da vida cotidiana, em que as mais banais emoções são passíveis de uma intervenção medicamentosa. Em contrapartida às drogas ilícitas, que estão imersas numa atmosfera de um moralismo que reprime tanto seu uso quanto o debate sobre sua descriminalização e regulamentação, aqui estamos situados no registro do aumento da oferta dos psicofármacos, incrementando os lucros exorbitantes da indústria farmacêutica. Este debate se insere no processo pelo qual há uma relação eticamente questionável entre os laboratórios e as pesquisas científicas, que pode ser acompanhado detalhadamente no trabalho de Marcia Angell, ex-editora-chefe do periódico científico New England Journal of Medicine e pesquisadora do Departamento de Medicina Social da Harvard Medical School (Angell, 2007).

O tema envolve não apenas uma perspectiva interna à produção científica e aos campos médico e bioquímico, mas insere o problema dentro da necessidade de se realizar uma discussão sociológica mais ampla e crítica, conforme feito por Pickersgill (2014), tangenciando esse campo de problemas, ligando à controvérsia sobre o DSM-5. O autor correlaciona a produção científica envolvendo o manual DSM-5 na perspectiva de uma sociologia da crítica a respeito da medicalização da sociedade. Dessa forma, o tema envolve vários atores sociais e se situa nas bordas dos campos da medicina social, da crítica sociológica, da psicologia, economia, política e das coberturas midiáticas.

Com efeito, a questão da medicalização carrega uma polissemia conceitual. Camargo (2013) examina o processo historicizante do conceito, elegendo a definição de medicalização como o processo de transformação de problemas anteriormente não médicos em problemas médicos. Para o autor, o primeiro desafio com relação ao conceito de medicalização seria o de "examinar em casos concretos como se dá a (re)construção ou expansão de categorias diagnósticas, explicitando os processos subjacentes" (Camargo, 2013, p. 845).

A questão da medicalização exigiria maior distinção e um estudo conceitual mais amplo, pois envolve diversos processos, até para não situar o tema dentro de um panorama simples, o que definitivamente não é. A complexidade passa, primordialmente, por definir o que é um problema médico. Camargo cita como exemplo o caso do HIV e aids, que não existiam no horizonte do conhecimento médico até a década de 1980. Posteriormente, com o avanço das pesquisas e o consequente aprimoramento dos coquetéis, a questão da aids passa a ser controlada pela prescrição medicamentosa, ou o ato de medicar, para fazer frente ao vírus do HIV. Portanto medicar, aqui, seria algo positivo.

Entretanto existiria "a extensão de possibilidades de intervenção a serviço de interesses econômicos descompromissados com os propósitos éticos associados

3 Este termo será utilizado doravante para diferenciar do que se entende por medicalização, estritamente, algo mais amplo e prática iniciada no século XIX (Foucault, 2014). à lógica da saúde" (Camargo, 2013, p. 845). Assim, o processo pelo qual a modernidade e os processos de transformação social foram remetidos à interseção com a medicina moderna demandam a explicitação da diferença entre medicalização e sua vertente, a medicamentalização: "Uma das vertentes da medicalização se vincula ao crescente uso dos medicamentos como forma de cura, alívio ou solução para as mais diversas questões ligadas à vida cotidiana. Esse processo tem sido nomeado 'medicamentalização"' (Vargas \& Campos, 2019, p. 85).

Assim, o tema requer um detalhado e cuidadoso estudo historiográfico, o que não é o caso aqui, mas parte-se do pressuposto de que o processo de medicamentalização, entendido como a apreensão médica a partir de situações não necessariamente médicas, é o pano de fundo de um processo mais específico. Esse processo ganha contornos específicos com a classe dos psicofármacos. Ou seja, há algumas nuances importantes de serem frisadas no concernente ao modo pelo qual emoções, reações e comportamentos psicológicos em geral, ou os seus excessos (ou déficits), podem ser tidos como problemas médicos. Isso se denomina psicofarmacologização.

Se recuarmos um pouco mais além dessa localização do incremento da atividade de psicofarmacologização desde a última metade do século XX, pode-se contextualizar essa atividade na perspectiva da medicalização das sociedades ocidentais, processo iniciado no século XIX, enredado na trama biopolítica, na qual Foucault $(2008,2014)$ situa o nascimento da medicina moderna.

Iniciada como prática de higiene social na Europa, a medicalização incidiu sobre os corpos de forma a promover o ideário da saúde no lugar anteriormente conferido à salvação. A noção de salvação estava inscrita no cenário pré-moderno, ligado a uma hermenêutica religiosa. Constituiu-se, no lugar da retórica salvacionista, a clínica e medicina social, de forma que as categorias de normal, anormal e patológico passaram a dominar os discursos de saúde, notadamente na medicina e nas políticas públicas, na esteira da configuração do que Foucault denominou de processo de normalização.

A medicina não deve mais ser apenas o corpus de técnicas da cura e do saber que elas requerem; envolverá também um conhecimento do homem saudável, isto é, ao mesmo tempo uma experiência do homem não doente e uma definição do homem modelo. Na gestão da existência humana, toma uma postura normativa que não a autoriza apenas a distribuir conselhos de vida equilibrada, mas a reger as relações físicas e morais do indivíduo e da sociedade em que vive. (Foucault, 2014, p. 39)

Essa medicina faz coincidir o corpo do doente com o "corpo" da doença, no encontro propiciado pela caracterização da anatomia patológica. Qualquer experiência de doença se inscreve precisamente na localização do espaço do corpo do doente, de forma que estar doente deixa de ser 
uma experiência de produção narrativa a partir do próprio doente, e passa a ser compreendida como uma disfunção que se caracteriza por lesões visíveis no organismo.

Realizar essa contextualização é importante, pois situa o pano de fundo que permite questionar quando e por que a questão da medicalização-medicamentalizaçãopsicofarmacologização se torna efetivamente uma questão, um problema a ser investigado. Nesse sentido, a ressonância deste estudo encontra apoio na indagação de Conrad (2007), na medida em que o autor se interessa sobre a sustentação social da jurisdição médica e as implicações sociais desse desenvolvimento.

No lugar de adentrar o campo de uma suposta colonização médica, realçando os aspectos que identificam apenas um incremento da indústria farmacêutica, Conrad (2007) se interessa em investigar em que medida ocorre diminuição da tolerância aos sintomas, o que faz haver o aumento pela demanda por psicofármacos. Há aí uma interrogação sobre a passagem e transformação de aspectos da vida cotidiana para a tradução de definição em termos médicos. Assim, Conrad (2007) sustenta: “'Medicalização' descreve um processo no qual problemas não médicos tornam-se definidos e tratados como problemas médicos, geralmente em termos de doenças e transtornos" (p. 4, tradução nossa).

Nesse sentido, a discussão sobre o normal e o patológico é necessária. Canguilhem (2014) organiza importantes coordenadas a respeito dos limites entre os domínios do normal e do patológico. Essa problemática ganha consistência a partir do questionamento sobre se a caracterização do estado patológico deriva de uma modificação quantitativa do estado normal. Realizando uma crítica contundente a um modelo positivista de interpretação sobre saúde e doença, o autor relativiza a ideia de uma norma a partir da qual se poderia delimitar esses conceitos. Normal e patológico, saúde e doença, devem ser compreendidos dentro de um fluxo intercambiante de processos complexos que acometem a totalidade da vida, e não podem se resumir a meras alterações quantitativas.

Por isso mesmo o debate sobre o processo de aumento da medicalização a partir dos anos 1950, com o impulso da psicofarmacologia, requer outra visada. Se uma leitura a respeito das emoções, sentimentos e comportamentos em geral foi pautada na noção de um desequilíbrio químico, uma teoria meramente quantitativa a respeito do normal e do patológico é insuficiente na compreensão do fenômeno da psicofarmacologização. Nesse sentido, o objetivo deste artigo é realizar um exame crítico sobre as condições do aumento da demanda de psicofármacos na contemporaneidade. Não se pretende esgotar a discussão, tampouco menosprezar os efeitos benéficos que os campos médico, científico e farmacológico trouxeram para a sociedade, mas oferecer subsídios para um diálogo interdisciplinar de problematização. Assim, este estudo se pautará em uma reflexão genealógica (Foucault, 1979) sobre alguns elementos concernentes a essa discussão.
As coordenadas do estudo se inserem na problemática do mal-estar na atualidade (Birman, 2007), organizando este objeto de estudo dentro de uma proposta de reflexão social e sobretudo política. Esse debate está inserido na constituição de uma questão posta às ciências humanas sobre a toxicomania. Além disso, a questão será relacionada com o funcionamento da indústria farmacêutica na capilarização do tecido social, tendo como pano de fundo a hipótese de que a relação com o universo das drogas se insere em uma banalização do mal, tema tratado na filosofia política por Arendt (1999). Portanto este é um estudo que se situa nas bordas dos saberes, não apenas médico e bioquímico, mas na interseção com os saberes das humanidades, dado que se exige uma leitura ampla e social sobre o fenômeno da psicofarmacologização.

\section{Psicofarmacologização do mal-estar}

A proposta de reflexão aqui adensada se pauta na cartografia de um panorama social determinado. Sem pretender recorrer a uma partidarização em prol ou contra o uso de drogas, problematiza-se um diagnóstico, já que a questão se localiza também no domínio do campo médico. O diagnóstico de um uso intenso de drogas na atualidade se inscreve em um contexto cultural que favorece a emergência e oferta de novas modalidades de drogas e se pauta na esteira de um trinômio que Birman (2014) sustenta como sendo tecido pelas relações entre a droga, performance e a medicalização da existência, que se realiza pela mediação da psiquiatria.

Nessa seara, chama a atenção que, ao mesmo tempo em que uma grande ofensiva social se manifesta atualmente na defesa da proibição das drogas ilícitas, um silenciamento acerca do aumento da utilização de psicofármacos se faz presente, o que se justifica pelo ideário de saúde e bem-estar que é veiculado. A ideia de realizar uma tematização acerca das drogas, de modo geral, na atualidade se inscreve, portanto, na identificação de uma banalidade do mal psicofarmacológico. No entanto, para além da identificação desse paradoxo, não importa tanto se é o uso de uma droga lícita ou ilícita. $O$ recorte que interessa realizar aqui, por ser incrementada pela indústria farmacêutica, é da demanda crescente por psicofármacos e a relação com seu uso. Um ponto importante a ser realçado neste estudo é o quanto essa engrenagem, no lugar de promover benefícios, pode gerar malefícios se não for exercida de forma crítica.

A ideia da banalidade do mal é retirada da leitura que Arendt (1999) faz do julgamento de Adolf Eichmann a respeito dos crimes no nazismo. Eichmann era próximo a Hitler e um dos maiores responsáveis pela dizimação em massa de judeus na Alemanha nazista. Dois aspectos chamam a atenção no registro de Arendt. Um deles é o da surpresa advinda de certa frieza em sua narrativa quando perguntado sobre os crimes. Esperava-se um ser sanguinário, horrendo. No entanto seu comportamento e suas falas denotaram a distância dessa expectativa, 
na medida em que o que se viu foi um funcionário público que respondia que apenas fazia seu trabalho e que almejava crescer como qualquer outro trabalhador.

Eichmann dizia que era mero instrumento da maquinaria nazista, não sendo responsável por bater ou matar pessoas e que, portanto, não se sentia culpado. Afirmando que apenas cumpria ordens, ele se colocara como mero funcionário, um burocrata. Esse aspecto acionava a reação por parte dos que acompanhavam o julgamento. A inquietação provocada nos espectadores encontrava uma resposta de se tratar de uma frieza típica da monstruosidade perversa. A filósofa política Hannah Arendt também captou esse registro, estando ela naquele momento como enviada do jornal The New York Times para cobrir o julgamento. E aí se coloca o segundo registro, no qual Arendt formula sua construção sobre a banalidade do mal. O problema do mal se coloca, para Arendt, não a partir de um paradigma moral, mas dentro de uma perspectiva política.

Entendendo exercer sua função burocrática dentro de um funcionamento, Eichmann não entra em contato com a reflexão de sua ação no mundo, desconsiderando seus efeitos. Esse combustível é um recurso utilizado na promoção de cultura de massas burocraticamente organizada, na qual a crítica e a autocrítica não se realizam, apenas se cumprem. Aí o problema do mal se banaliza.

Dessa forma, o problema da psicofarmacologização encontra suporte para sua propagação e sedimentação na cultura atual a partir do imperativo de performance, e então a dimensão do excesso de psicofármacos pode resvalar para um mal se suprimida a crítica que balize seu uso, podendo se inscrever aí a banalidade do mal psicofarmacológico. Há uma retroalimentação da relação entre a oferta e a procura catapultada por uma indústria farmacêutica que produz uma pílula para a regulação neuroquímica na intenção de neutralizar os efeitos emocionais advindos da instabilidade de alguma situação da vida cotidiana.

$\mathrm{O}$ pano de fundo desse panorama se inscreve na impossibilidade da vivência do que Han (2017) denomina como negativo. Segundo o filósofo coreano, há, na atualidade, um excesso de positividade, que seria o equivalente da hiperatividade generalizada. Não é sem motivo que um dos transtornos mais em evidência na atualidade é o transtorno do déficit de atenção com hiperatividade (TDAH).

$\mathrm{Na}$ lógica do TDAH há excesso de atividade. A ideia é que todos devem ser produtivos e performáticos, de forma que quem não se encaixa nessas demandas é relegado ao limbo da patologização. Assim, as vivências e flutuações emocionais facilmente são passíveis de uma inscrição psicopatológica, e aí há a oferta de um psicofármaco para neutralizar os efeitos daquele transtorno. Portanto, a partir da lógica da oferta e da demanda para o consumo, os efeitos da psicofarmacologização excessiva, para além da ordem de uma necessidade, acabam por ficar nublados, o que insere a perspectiva da banalidade do mal psicofarmacológico.

O imperativo da performance na atualidade estaria pautado na continuidade do que, na década de 1970, Lasch (1983) denominou de cultura do narcisismo.
Nesse caldo cultural, os indivíduos têm necessidade de estar no centro das atenções, instigados pela lógica do autocentramento e da competitividade. Os indivíduos se sentem aquém em relação às imposições de uma proatividade desenfreada, o que justifica o aumento expressivo da chamada depressão na atualidade. Aí se situa o triunfo do projeto de uma pomposa indústria farmacêutica, que vende a esperança da garantia de um objeto que restaure as potencialidades individuais dos "fatigados de serem si mesmos" (Ehrenberg, 2000).

A compreensão da lógica neoliberal é fundamental para dispor as coordenadas do contexto sócio-histórico da atualidade, entendendo essa lógica como a contrapartida do Estado de bem-estar social estabelecido no período após a II Guerra Mundial. A sociedade, na dita pósmodernidade (Bauman, 1998), entrou em processo de desconstrução, de forma que foi substituída pelo mercado. É nesse imbróglio que Birman (2014) compreende que as noções de cidadão e soberania popular, que caracterizaram a modernidade, foram substituídas pela figura do consumidor e as transformações evidenciam que o neoliberalismo vigente na atualidade não se configura como uma retomada do liberalismo do século XIX.

Então, a sociedade transformada em mercado impõe um risco constante aos indivíduos, que frequentemente necessitam estar em movimento, numa equivalência ao funcionamento como empresas de si mesmos (Foucault, 2008). Por isso, a psicofarmacologização na atualidade tem um solo fértil, na medida em que a psiquiatria surge como poderoso dispositivo que incide sobre os corpos, na regulação do mal-estar individual e social.

Esse processo de psicofarmacologização do malestar se forjou no seio das sociedades neoliberais a partir da conjugação com os discursos da neurobiologia e da psicofarmacologia. Com base em uma visão estritamente fisicalista, essas modalidades de discurso, amparando uma interpretação totalizante a respeito dos indivíduos, incidem na leitura do corpo como palco de processamento de exterioridades ou, dito de outra forma, de estímulos advindos do mundo externo. Dessa forma, o sofrimento, restrito a uma leitura da desregulação bioquímica, acarreta prejuízo simbólico, rechaçando o aspecto sócio-histórico da doença e relegando ao limbo a relação do corpo com a linguagem (Forrester, 1983).

No centro disto tudo, a compulsão ganha estatuto privilegiado nas formas de subjetivação na atualidade (Gondar, 2001), pois ela se amplia em sua equiparação à experiência das adicções, expandindo-se para outros objetos. O corpo se transformou no palco em que se enuncia inequivocamente o mal-estar. Imagina-se que sempre há algo por se fazer para aumentar a performance corpórea.

Assim é que a narrativa do mal-estar na atualidade se exemplifica primordialmente num estado de estresse permanente, indicando a pregnância assumida no registro do corpo que denota a falha no mecanismo da angústia-sinal no psiquismo, ou seja, uma falha na antecipação de uma iminência de perigo. Símbolo maior 
disso é o retorno intenso daquilo que era denominado por Freud de neurose de angústia, a atual síndrome do pânico (Pereira, 2008). Esse é um exemplo de como as drogas psicofarmacológicas são incentivadas como pretensoras da regulação do mal-estar presentificado no corpo. No entanto esse corpo da atualidade, isolado de seu sentido simbólico, acaba sendo subsumido à dimensão orgânica, na medida em que o corpo está posto como um epifenômeno do que acontece a nível cerebral.

Dessa forma, há um fascínio exercido no imaginário dos usuários no ideal de saúde, bem-estar e juventude eterna. Isso se articula intimamente no ideal do marketing, que produz uma demanda constante de produtos e serviços a serem consumidos. Isso não pode ser separado das práticas de medicalização do Ocidente, iniciadas no século XIX.

\section{Farmacologização dos lucros cotidianos}

Tendo realizado essa contextualização, o que se deseja agora é ressaltar algumas pontuações a respeito do silenciamento sobre a profusão do uso de drogas lícitas. Não se pretende esgotar a discussão a respeito das drogas, dadas as múltiplas e amplas leituras possíveis acerca dessa grande problemática, mas oferecer algumas pistas que indicam as formas pelas quais a banalidade do mal psicofarmacológico se intercruza profundamente na dinâmica da vida atual.

Historicamente, o homem sempre utilizou substâncias que alterassem organicamente sua dinâmica psíquica. Na busca de outra relação com o mundo a partir da alteração da organização bioquímica corporal, a apreensão do universo das drogas sempre foi algo próximo dos indivíduos em sua relação com a realidade. Desde fins do século XVIII, houve uma intensa profusão no campo da ciência, nas artes e na medicina da experimentação de drogas, como historiciza Cohen (2014).

$\mathrm{Na}$ contextualização dessa atmosfera da experimentação de drogas, principalmente no século XIX, há a identificação de um crescente interesse no desenvolvimento da experimentação de drogas, sejam como catalizadoras de novas percepções do mundo, sejam com finalidades terapêuticas. O questionamento é sobre o pano de fundo das variáveis sociais e históricas que se sobrepõem na organização desse diagnóstico.

Vaz (2015) afirma que um modo de estimar as diferenças entre a subjetividade moderna e a contemporânea é a surpreendente incidência, hoje, de doenças mentais. Há um expressivo aumento do número das entidades diagnósticas, em um ritmo que possibilita a inserção dos indivíduos dentro do enquadramento da categoria de "doente". O autor afirma que mais interessante do que pensar se realmente há um número maior de doenças pois há uma hermenêutica na concepção de doença que é diferente - é se questionar por que nossos contemporâneos não se espantam com tamanha prevalência de doenças. Haveria uma fé irrestrita no enunciado de um grave problema de saúde pública, confiando nas instituições que afirmam sua existência, o que faz haver uma lógica que contraria a suposição de desviantes como minoria em uma sociedade. Atualmente, a lógica é do enquadramento da maioria na categoria de desviantes:

o diagnóstico de doenças mentais parece ter afrouxado seu vínculo com a infração de regras, substituindo-o pelos nexos com a sensação de bemestar. Ou ainda, se o conceito de doença mental presume que só há doença quando há desvio em relação a uma expectativa social, na Modernidade, essa expectativa estava ancorada na regularidade do comportamento; já na atualidade, a expectativa socialmente induzida é a de ser feliz como se deve; portanto, sofrer, não ser tão feliz como se tem direito, é desviar, é ter um problema de saúde mental. Daí a relevância atual de doenças como depressão, fobia social, estresse pós-traumático, ansiedade generalizada etc. (Vaz, 2015, p. 55)

Na modernidade, a anatomia assumiu um lugar privilegiado no tocante às doenças orgânicas. O campo das doenças mentais, entretanto, permanecia carente dessa organização, estando referida ao campo moral. Surgiu, então, nessa seara, um campo fértil para o tratamento das paralisias histéricas a partir da hipnose. Se de um lado a ausência de contrapartida anatômica provocava um nó na comunidade científica a respeito desses fenômenos, as curas pela hipnose eram maneiras de definir um espaço para essas modalidades de sofrimento, definindo um espaço de doença mental.

Assim, o sintoma apareceu como organizador da doença, sendo que, na doença orgânica, essa relação estaria presente, o que não ocorreria com a doença mental. Nesse sentido, Vaz (2015) aponta que a dissociação entre sintoma e contrapartida anatômica foi o que possibilitou "vender doenças", tendo a ideia de fator de risco como regulador dessa relação.

A poção mágica constantemente buscada incide em um contexto ao qual se faz necessária a retomada da leitura de Borch-Jacobsen (2013). O autor considera que sua postura crítica não seja em relação aos medicamentos em si, mas, sim, contra a indústria que transforma seu uso em uma multiplicadora de lucros. Os medicamentos ajudaram a criar condições outras de tratamento, ampliando-as. No entanto o ponto nodal se refere a uma exacerbação do uso indiscriminado de medicamentos e, mais especificamente, no campo psicofarmacológico (Whitaker, 2002, 2010).

Borch-Jacobsen (2013) se interroga sobre o fato de os medicamentos não serem submetidos a um controle rigoroso, não havendo uma exigente inspeção sobre a relação risco/benefício, a fim de evitar os riscos de perigos inúteis. Sua constatação é que esse rigor é uma falácia e que um caráter perverso regula a disseminação dos psicofármacos. Prova disso são os diversos escândalos que acometem a indústria farmacêutica, levandonos a refletir se esses escândalos seriam exceções ou se seriam a regra. Por meio de inúmeros casos, 
Borch-Jacobsen (2013) demonstra que os escândalos farmacêuticos apontam para uma maquinaria que visa os lucros das empresas: desde um marketing cínico, passando por pesquisas e ensaios laboratoriais manipulados, até as corrupções envolvendo agências sanitárias e o débil sistema do que o autor chama de uma farmacovigilância. Os escândalos não são, portanto, casos isolados, mas tem relação íntima com um setor industrial estratégico envolvendo a indústria farmacêutica, caracterizando o que chamo aqui de banalidade do mal psicofarmacológico.

Vários casos de crimes cometidos relativos à indústria farmacêutica são levantados por BorchJacobsen (2013), como o remédio para controle de colesterol que fez que a pele das pessoas se assemelhasse à de crocodilos. Mais especificamente com relação ao campo dos psicofármacos, no caso do famoso Prozac ${ }^{4}$, o autor demonstra ter havido, durante décadas, casos de suicídios em pessoas que usavam o medicamento. Um dos argumentos de venda do Prozac repousava sobre a afirmação de que este não apresentava efeitos secundários indesejáveis, contrariamente aos antidepressivos de primeira e segunda gerações.

Apesar de inúmeros processos contra o laboratório produtor do Prozac em fins do ano de 1991, a defesa do laboratório alegava que o suicídio e os atos hostis refletiam questões do paciente e não uma relação causal com os antidepressivos inibidores seletivos de receptação de serotonina (ISRS). Foi preciso quase uma década para que um estudo chegasse à conclusão de que pensamentos suicidas poderiam ser provocados pela administração de Zoloft, um antidepressivo ISRS da companhia Pfizer.

No entanto documentos revelavam que já em 1978, dez anos antes da comercialização do Prozac, a Eli Lilly, companhia que o produzia, possuía pesquisas que constatavam que o medicamento causava, em algumas pessoas, reversão de depressão profunda em intensa agitação e até o desenvolvimento de psicose. Mesmo assim, por uma série de acordos, menções necessárias de possibilidade de contraindicações, brechas jurídicas encontradas, permitiram que a companhia continuasse produzindo o medicamento.

Com efeito, ao contrário do que é veiculado pela ideologia neoliberal, o interesse das companhias não coincide com o interesse público. De fato, existe um permanente conflito de interesses, pois o objetivo primeiro das companhias farmacêuticas não é o de proteger a saúde das populações, mas o de assegurar um retorno financeiro sobre seus investimentos o mais elevado possível a seus acionistas.

A indústria farmacêutica não tem preocupação com a saúde das pessoas, necessariamente, mas, sobretudo, com seus lucros. Prova disso é que a grande maioria dos medicamentos disponíveis atualmente no mercado, nos

4 No estudo, Borch-Jacobsen (2013) mostra que depois da chegada do Prozac (fluoxetina), da companhia Eli Lilly, no mercado, em fins dos anos 1980, dezenas de milhões de pessoas no mundo todo consumiram antidepressivos ISRS (Inibidores seletivos de receptação de serotonina), seja o Prozac, Zoloft, Paxil, Luvox ou Cymbalta. Nos Estados Unidos, o consumo de antidepressivos aumentou 400\% entre 2005 e 2008. países desenvolvidos, não são os de tratamento curativo, mas aqueles destinados a prevenir uma deterioração ou a assegurar o bom funcionamento do organismo, otimizando seu desempenho.

O resultado disso é que o paciente se torna um cliente: ele é fidelizado, atado ao seu medicamento. Assim, uma espécie de caça às bruxas em torno das taxas de hormônios e elementos químicos do corpo que possam estar desregulados é realizada. Esse movimento é favorecido pela alta disponibilidade e sofisticação das técnicas laboratoriais e de imageamento corpóreo. Essa caça resulta em um movimento em que o menor sinal de desequilíbrio orgânico é rastreado, muitas vezes, por exames cada vez mais minuciosos.

As "lifestyle drugs" - literalmente, "médicaments style de vie" (drogas estilo de vida) que traduziremos por "médicaments qualité de vie" (drogas qualidade de vida) - são as drogas que não visam a curar uma doença pondo em risco a vida de uma pessoa, mas a aumentar seu bem-estar ou seu conforto: ansiolíticos e "tranquilizantes" de todos os gêneros, drogas contra o excesso de peso, o refluxo gástrico ou os ataques de calor da menopausa, soníferos, analgésicos. As "drogas estimulantes" são substâncias que visam "melhorar" o corpo e sua performance. Fazem parte disso os produtos esportivos dopantes e os psicoestimulantes utilizados por estudantes para passar em seus exames, assim como o hormônio do crescimento sintético ou os tratamentos contra a calvície... E o que dizer do Viagra? Ele é utilizado ao mesmo tempo por alguns para remediar a "disfunção erétil" e por outros a grande maioria - para incrementar sua performance sexual. No limite, não se trata mais de curar o que quer que seja, mas de otimizar o bem-estar e o rendimento do corpo, exatamente como se otimiza o rendimento de um campo agrícola com fertilizantes e pesticidas. (Borch-Jacobsen, 2013, p. 81, tradução nossa)

Inserida na classe política e aliada a determinados pesquisadores e grupos de pesquisa, a indústria farmacêutica entra em ação na formulação de algum bem medicamentoso que virtualmente afaste o fantasma da doença. Assim, as fronteiras entre o normal e o patológico restam muito tênues e o mercado dos medicamentos se estende sempre mais. O caso da disfunção erétil é um exemplo da intervenção medicamentosa em vários âmbitos da vida, nesse caso, inserida no processo de medicalização da sexualidade (Giami, 2009).

$\mathrm{Na}$ conjugação da produção medicamentosa com a legitimação teórico-científica, há o respaldo propiciado pelos manuais de psiquiatria, que conferem uma ratificação no sentido da produção de novas doenças. Como exemplo, podemos citar o trabalho de Gonçalves, Dantas e Bonzato (2015), que afirmam, no tocante à síndrome psicótica atenuada (SdPA), que "os membros do Grupo de Trabalho de Transtornos Psicóticos do DSM-5 não estavam dando peso 
suficiente às muitas consequências perigosas que poderiam advir com a oficialização desta categoria" (p. 140).

Esse debate sobre os manuais de psiquiatria é abordado por Russo e Venâncio (2006). As autoras sustentam que a primeira versão do DSM, de 1952, era baseada em uma compreensão "psicossocial" da doença mental, concebida como uma reação a problemas da vida e situações de dificuldade impingidas individualmente. A influência exercida pela psicanálise se evidenciou pelo uso frequente de noções como "mecanismos de defesa", "neurose" e "conflito neurótico".

$\mathrm{Na}$ versão subsequente do manual, publicada em 1968 - o DSM II -, o modo psicanalítico de compreensão da perturbação mental se tornou ainda mais evidente. Ela é vista como a expressão visível de uma realidade psicológica oculta a ser interpretada no curso do diagnóstico ou do tratamento. Apesar de ter aumentado o número de diagnósticos, ele permanecia sendo usado mais como um instrumento para fins administrativos, sem muito peso clínico. Foi nessa versão que surgiu pela primeira vez uma seção dedicada a transtornos comportamentais na infância e na adolescência. Também trazia uma nova seção voltada à descrição de desvios de sexualidade, incluindo aí a homossexualidade na lista de transtornos mentais, o que gerou muita polêmica e contestação por grupos gays.

Já na passagem para a terceira versão, em 1980, uma ruptura se deu em três níveis, que se articulam entre si: no nível da estrutura conceitual, rompeu com o ecletismo das classificações, além do afastamento, nessa versão, do referencial psicanalítico. Esse discurso, que oferecia as coordenadas epistêmicas nas primeiras versões, foi sendo substituído por um código mais cientifico. A ideia é que o DSM não sofresse a influência de nenhuma vertente teórica que pudesse supostamente manchar sua neutralidade, sendo proclamado assim um manual a-teórico, baseado em princípios de testabilidade e verificação, a partir dos quais cada transtorno é identificado por critérios acessíveis à observação e mensuração empírica. O pressuposto empiricista implicado em uma posição "a-teórica" e, por isso, objetiva, tem afinidades evidentes com uma visão fisicalista da perturbação mental.

Uma das principais consequências dessa ruptura foi o abandono da concepção do sintoma como signo e sua definição enquanto sinal. O pressuposto empiricista deixava de lado uma hermenêutica do sintoma para se restringirà tarefa diagnóstica de uma detalhada observação de comportamentos e atitudes. Essa perspectiva põe em marcha uma inequívoca ampliação do número de categorias diagnósticas e favorece diretamente a produção de medicamentos, pois, para cada categoria e seus derivados, há a oferta de novos medicamentos. Esse movimento tem se ampliado cada vez mais e atingido seus alvos cada vez mais cedo.

Caso emblemático disso se revela no drama de adultos, mas também de adolescentes e até crianças consumindo de modo crescente os psicofármacos indiscriminadamente (Azevedo, 2018). As crianças começam a ser diagnosticadas e medicalizadas precocemente, seduzidas que são aos imperativos da ação e da performance escolar. Esse já um modelo que anuncia o projeto que impulsiona a pressão individual e a competividade na organização das contingências sociais e econômicas de produtividade e proatividade, atreladas que estão ao mundo neoliberal.

\section{Considerações finais}

Este ensaio buscou realizar uma inserção não totalizante na problemática da interface da lógica econômica neoliberal atual com a produção de novos modos de ser no mundo. Este exercício de problematização tomou como eixo a questão do entrelaçamento da oferta da indústria farmacêutica, sobretudo com ênfase nos psicofármacos, e a demanda por novos instrumentos bioquímicos que incidem no imaginário do incremento da performance e das potências dos indivíduos.

Esse processo se iniciou dentro da perspectiva do fenômeno da medicalização da vida. Abordou-se a complexidade do tema na medida em que este atinge vários estratos e âmbitos da vida atual e em todas as faixas-etárias, em todos os gêneros, passando à psicofarmacologização da vida sexual. Devido à extensão a diversos campos do vivente e da sociedade, esse fenômeno demanda perspectivas ampliadas de problematização e compreensão.

Não é sem razão o fato de haver uma inflação diagnóstica, como relata o editor do DSM-IV, Frances (2013). No reconhecimento do poder de ação na expansão da psiquiatria, o autor sublinha os fortes impactos, principalmente na infância:

Ainda que tenhamos sido enfadonhamente modestos em nossos objetivos, obsessivamente meticulosos em nossos métodos e rigidamente conservadores em nosso produto, falhamos ao predizer ou prevenir três novas falsas epidemias de transtornos mentais em crianças - autismo, déficit de atenção e transtorno bipolar na infância. Ou seja, é claro o poder de produção de modificações nos modos de pensar e agir sobre o sofrimento mental, chegando, no limite, ao aumento da prevalência de determinadas condições clínicas em função da alteração nos critérios de cada nova edição lançada. (Frances, 2013, p. XIV, tradução nossa)

A ideia foi apontar um eixo importante nessa problemática, que foi chamado de banalidade do mal psicofarmacológico. Isso porque a otimização dessa lógica encontra solo fértil na ausência da reflexão em torno dos malefícios advindos dessa própria lógica. Portanto, descentrando a questão de uma ótica apenas médica, mas colocando luz sobre as tensões inerentes às produções diagnóstica e farmacológica, este estudo pretendeu se situar numa linha de crítica sociológica acerca do fenômeno.

A título de finalização, há um aspecto importante de ser ressaltado, que tem a ver com a iluminação de 
determinadas regiões da produção científica que merecem um olhar atento. Trazer luz pode significar a necessidade de um olhar mais complexo, pois, com mais luz, há mais detalhes a serem vistos. Longe de significar colocar em xeque a produção científica, a ideia aqui foi justamente trazer mais elementos e tensões inerentes ao campo científico, contextualizando-o.

Esse aspecto diz respeito ao fato de saber se a relação entre os supostos benefícios e os riscos dos psicofármacos é positiva. Para isso, é preciso muitos anos de testes, o que não é feito em muitos casos, ou a diferença entre o medicamento e o placebo não é significativa (Kirsch et al., 2008). O problema não cessa de se agravar, pois as drogas que apresentam maior potencial em termos de negócios são aquelas de tratamento crônico.

Os benefícios do recurso a psicofármacos, se organizado de maneira a respeitar os limites psicodinâmicos, podem ser inúmeros, desde o apaziguamento da angústia até a possibilidade de organização subjetiva. Para isso, é preciso que haja uma imersão da compreensão psicodinâmica da subjetividade. No entanto os efeitos da banalidade do mal psicofarmacológico são severos, na medida em que os limiares entre o normal e o patológico são atenuados, ou até tornados invisíveis e, assim, a distinção entre os processos de saúde e doença se tornam obnubilados.

A dimensão do excesso de drogas psicofarmacológicas pode produzir um comportamento de fidelização do consumidor ávido por uma pílula que aplaque seu malestar. E essa engrenagem se retroalimenta a partir de uma necessidade criada e, muitas vezes, com um equivalente nosográfico disponível nos manuais de psiquiatria. Como lembra Derrida (2015), a palavra grega pharmakon pode significar tanto "remédio" quanto "veneno".

\section{The banality of psychopharmacological evil in times of performance}

Abstract: This paper traces a path that begins by identifying the phenomenon known as medicalization of life. Since this object of study is not only a medical issue, requiring an articulation with other areas of knowledge, the study proposes a genealogy that articulates medical and social criticism on this phenomenon, combining medicine, sociology, psychology, economics, and political theory. Such tapestry is weaved against the backdrop of current demands for autonomy and performance, in the context of increasing psychopharmacological urges. If the benefits of drug administration can provide subjective wellbeing, the excesses or the banality of psychopharmacological evil, on the other hand, blur the boundaries between normal and pathological.

Keywords: psychopharmacology, performance, neoliberalism, Pharmaceutical industry.

\section{La banalité du mal psychopharmacologique en temps de performance}

Résumé : Cet article retrace un chemin qui commence par l'identification du phénomène connu sous le nom de médicalisation de la vie. Puisque cet objet d'étude n'est pas seulement une question médicale, nécessitant une articulation avec d'autres domaines de connaissance, l'étude propose une généalogie qui articule la critique médicale et sociale sur ce phénomène, en combinant la médecine, la sociologie, la psychologie, l'économie et la théorie politique. Cette tapisserie est tissé sur fond d'exigences actuelles d'autonomie et de performance, dans un contexte de demandes psychopharmacologique croissantes. Si les bénéfices de l'administration de médicaments peuvent procurer un bien-être subjectif, les excès ou la banalité du mal psychopharmacologique, en revanche, brouille les frontières entre normal et pathologique.

Mots-clés : psychopharmacologisation, performance, néolibéralisme, industrie pharmaceutique.

\section{La banalidad del mal psicofarmacológico en tiempos de performance}

Resumen: Este artículo pretende seguir un camino que parte de la identificación del fenómeno de la medicalización de la vida. El estudio se organizará dentro de una perspectiva genealógica, debido a la importancia de conocer que este objeto de estudio no se limita a un tema médico, sino que requiere un esfuerzo para articularse con otras áreas del conocimiento. Así, esta genealogía articula la problemática médica con la crítica social sobre este fenómeno, combinando la medicina, la sociología, la psicología, la economía y la teoría política. Esta trama se organizará en el contexto de las demandas de autonomía y desempeño de la actualidad, en el contexto de una mayor demanda psicofarmacológica. Si, por un lado, los beneficios de la administración de medicamentos pueden proporcionar un bienestar subjetivo, por otro, los excesos o la banalidad del mal psicofarmacológico hacen que los límites entre lo normal y lo patológico sean opacos.

Palabras clave: psicofarmacologización, performance, neoliberalismo, industria farmacéutica. 


\section{Referências}

Angell, M. (2007). A verdade sobre os laboratórios farmacêuticos. Rio de Janeiro, RJ: Record.

Arendt, H. (1999). Eichmmann em Jerusalém. São Paulo, SP: Companhia das Letras.

Azevedo, L. (2018). Medicalização das infâncias: entre os cuidados e os medicamentos. Psicologia USP, 29(3), 451-458. Recuperado de https://bit.ly/37fFDbc

Bauman, Z. (1998). O mal-estar da pós-modernidade. Rio de Janeiro, RJ: Zahar.

Birman, J. (2007). Mal-estar na atualidade: a psicanálise e as novas formas de subjetivação. Rio de Janeiro, RJ: Civilização Brasileira.

Birman, J. (2014). Drogas, performance e psiquiatrização na contemporaneidade [número especial]. Ágora, 17, 2337. Recuperado de https://bit.ly/3ljTR32

Borch-Jacobsen, M. (2013). Big pharma: une industrie toute-puissante qui joue avec notre santé. Paris: Éditions Les Arènes.

Camargo, K., Jr. (2013). Medicalização, farmacologização e imperialismo sanitário. Cadernos de Saúde Pública, 29(5), 844-846. Recuperado de https://bit.ly/3xf1r13

Canguilhem, G. (2014). O normal e o patológico ( $7 \mathrm{a}$ ed.). Rio de Janeiro, RJ: Forense Universitária.

Cohen, D. (2014). Freud e a cocaina: a história do uso da droga nos primórdios da psicanálise. Rio de Janeiro, RJ: Record.

Conrad, P. (2007). The medicalization of society: on the transformation of human conditions into treatable disorders. Baltimore: Johns Hopkins University Press.

Derrida, J. (2015). A farmácia de Platão. São Paulo, SP: Iluminuras.

Ehrenberg, A. (2000). La fatigue d'être soi: dépression et société. Paris: Odile Jacob.

Forrester, J. (1983). A linguagem e as origens da psicanálise. Rio de Janeiro, RJ. Imago.

Foucault, M. (1979). Microfísica do poder. Rio de Janeiro, RJ: Graal.

Foucault, M. (2008). Nascimento da biopolítica. São Paulo, SP: Martins Fontes.

Foucault, M. (2014). O nascimento da clínica (7a ed.). Rio de Janeiro, RJ: Forense Universitária.

Frances, A. (2013). Saving normal: an insider's revolt against out-of-control psychiatric diagnosis, DSM-5, big pharma, and medicalization of ordinary life. New York: HarperCollins Publishers.
Giami, A. (2009). Da impotência à disfunção erétil: destinos da medicalização da sexualidade. Physis, 19(3), 637658. Recuperado de https://bit.ly/2WMwwNg

Gonçalves, A. N., Dantas, C., \& Banzato, C. (2015). Valores conflitantes na produção do DSM-5: o "caso" da síndrome psicótica atenuada. Revista Latinoamericana de Psicopatologia Fundamental, 18(1), 139-151. Recuperado de https://bit.ly/3Ca5WOn

Gondar, J. (2001). Sobre as compulsões e dispositivo analítico. Ágora, 4(2), 25-35. Recuperado de https://bit.ly/3rSSNEr

Han, B. (2017). Sociedade do cansaço (E. P. Giachini, Trad., $2 \mathrm{a}$ ed.). Petrópolis, RJ: Vozes.

Kirsch, I., Deacon, B. J., Huedo-Medina, T. B., Scoboria, A., Moore, T. J., \& Johnson, B. T. (2008). Initial severity and antidepressant benefits: a meta-analysis of data submitted to the food and drug Administration. PLOS Medicine, 5(2), e45. doi: 10.1371/journal.pmed.0050045

Lasch, C. (1983). A cultura do narcisismo. Rio de Janeiro, RJ: Imago.

Pereira, M. (2008). Pânico e desamparo: um estudo psicanalítico. São Paulo, SP: Escuta.

Pickersgill, M. (2014). Debating DSM-5: diagnosis and the sociology of critique. Journal of Medical Ethics, 40(8), 521-525. Recuperado de https://bit.ly/2VjUjnk

Russo, J., \& Venâncio, A. (2006). Classificando as pessoas e suas perturbações: a "revolução terminológica" do DSM III. Revista Latinoamericana de Psicopatologia Fundamental, 9(3), 460-483. Recuperado de https://bit.ly/2VsHOFO

Vargas, A., \& Campos, M. (2019). Entre o cuidado e a medicamentalização: os debates sobre "trocar uma droga por outra". Revista Brasileira de Sociologia, 7(15), 81-103. Recuperado de https://bit.ly/3rOtxPD

Vaz, P. (2015). Do normal ao consumidor: conceito de doença e medicamento na contemporaneidade. Ágora, 18(1), 51-68. Recuperado de https://bit.ly/3A2vyuB

Whitaker, R. (2002). Mad in America: bad science, bad medicine, and the enduring mistreatment of the mentally ill. New York: Basic Books.

Whitaker, R. (2010). Anatomy of an epidemic: magic bullets, psychiatric drugs, and the astonishing rise of mental illness in America. New York: Broadway Books.

Recebido: 05/04/2020

Revisado: 22/12/2020

Aprovado: 26/07/2021 